\title{
Cooperation for Innovation in the European Union: Outlook and Evidences Using CIS for 15 European Countries
}

\author{
Luísa Carvalho $^{1}$ - Maria José Madeira ${ }^{2}$. \\ João Carvalho ${ }^{3}$ - Dulcineia Catarina Moura ${ }^{4}$. \\ Filipe P. Duarte 5
}

Received: 26 October 2016 / Accepted: 23 January 2018

(C) Springer Science+Business Media, LLC, part of Springer Nature 2018

\begin{abstract}
Cooperation for innovation is understood as an essential element in the innovation process of European firms. The aim is to compare how the different sources of information (external and internal) and cooperation for innovation are used in manufacturing and services in Europe using Community Innovation Survey (CIS) data for 15 European countries. The empirical study uses a sample of firms included in the CIS (2008), which covers 15 European countries and applies multivarious data analysis techniques to extract results. The results of this research suggest that firms use
\end{abstract}

Luísa Carvalho

luisam.carvalho@uab.pt

Maria José Madeira

maria.jose.madeira@ubi.pt

João Carvalho

joao.carvalho@ubi.pt

Dulcineia Catarina Moura

dulcineia.coito@ubi.pt

Filipe P. Duarte

filipeduarte@ubi.pt

1 Department of Social Sciences and Management, Universidade Aberta and CEFAGE-Universidade de Évora, Rua Braamcamp, $n^{\circ}$ 90, piso 5, 1250-052 Lisbon, Portugal

2 Management and Economics Department, University of Beira Interior, Pólo IV, 6200-209 Covilhã, Portugal

3 University of Beira Interior, Rua $1 .^{\circ}$ de Maio, Vivenda 3, 6230-339 Fundão, Portugal

4 University of Beira Interior, Rua Formosa, N. ${ }^{6} 66$, bloco B, 3. ${ }^{\circ}$, 6300-837 Guarda, Portugal

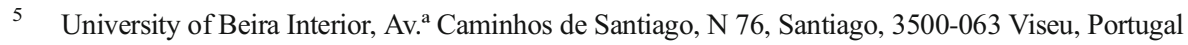


simultaneously different sources of information for cooperation, revealing different patterns of cooperation according to the activity sector in Europe. This paper brings some important insights about cooperation for innovation and suggests some patterns in Europe useful to design public policies, due de similar behavior of some countries grouped according with geography, development status or other economic features. Thus, this article seeks to frame the subject based on a literature review that raises a set of study hypotheses and presents an empirical study applied to cooperation for innovation in Europe using the CIS for 15 European countries.

Keywords Cooperation · CIS · European countries · Innovation · Patterns · Sector

\section{Introduction}

Cooperation is considered crucial to the innovation performance of firms. Several authors (Cohen and Levinthal 1990; Zeng et al. 2010; Srholec 2014) highlight the importance of sources of information and knowledge, as well as of cooperation for innovative performance (Cohen and Levinthal 1990; Silva and Leitão 2009; Zeng et al. 2010; Srholec 2014).

Studies underline, in particular, the relationship between firms and some specific resources, such as R\&D (De Marchi 2012), universities and research centers (Becker and Dietz 2004; Bullinger et al. 2010), clients (Faria et al. 2010; Jiménez-Zarco et al. 2011), and suppliers (Koschatzky 1999; De Marchi 2012).

Several studies on cooperation for innovation, using the Community Innovation Survey (CIS) database to several European countries, have been carried out (Tether 2002; Becker and Dietz 2004; Belderbos et al. 2006; Carvalho et al. 2015). Nevertheless, the subject of cooperation, using comparisons between countries, particularly in Europe, remains understudied from an empirical point of view (Carvalho et al. 2015).

Although some studies investigate the differences in the types of cooperation partners (Belderbos et al. 2006), the literature on this subject is still incipient, especially when regarding econometric studies applied to several European countries trying to find patterns of cooperation for innovation according to the sector.

This issue is particularly relevant as evidenced by the fact that many authors suggest differences regarding the innovation performance according to the sector (Evangelista 2000; Marsili and Verspagen 2002; Pires et al. 2008; Carvalho et al. 2013), which are reflected in different patterns of innovation. However, those focusing on understanding these differences in the innovative process, which, as known, is currently and increasingly based on networks and cooperation with different partners, are incipient. To cover this gap, this paper aims to answer to the research question: How the different sources of information and cooperation for innovation are used in manufacturing and services in Europe? In order to answer to the research question we have twofold: (1) understand how cooperation for innovation with external partners differs, in Europe, between manufacturing and services and (2) understand how cooperation for innovation with internal partners differs, in Europe, between manufacturing and services.

The paper proceeds as follows. Next, two sections provide a brief discussion of the key issues at stake and formulates the hypotheses. Follow sections introduce the empirical study, provides results and discussion principal components grouped by 
factor analysis based on the CIS micro-data, and provide a suggestion of patterns for cooperation based on the main factor analysis groups and by country. Finally provide some remarks about the results of the study.

\section{Cooperation for Innovation}

In a period where competition is global and technological development is extremely fast, the ability to innovate and adapt to change is fundamental for businesses. In this context, access to sources of information and organizational learning skills are recognized as essential to the innovation performance of firms.

The acquisition, per se, of these external resources may not be enough, as the transfer of knowledge often requires interactive learning between users and producers (Von Hippel 1976; Lundvall 1988). Firms operate in global markets and display patterns of cooperation, regarding the development of new products and processes (Richardson 1972), share complementary resources and mitigate risks (Miotti and Sachwald 2003).

However, the process of creating new knowledge requires absorptive capacity, which can be understood as the overall capacity of the firm to acquire and assimilate information and use it effectively to enhance its performance (Cohen and Levinthal 1990; Teece et al. 1997; Zahra and George 2002). Furthermore, cooperation helps to unlock internal constraints to innovation by facilitating access to external sources of knowledge that allow firms to benefit from the division of labor in the innovation process (Miotti and Sachwald 2003).

There are also strategic reasons that lead to the acknowledgement of cooperation based on innovation as the organizational response to the growing complexity of research and technology's swift progress (Child and Faulkner 1998; Arvanitis 2012). The role of collaborative approach when it comes to innovation has increased significantly in the era of open innovation (Enkel et al. 2009), resulting in the growing importance of innovation networks (Dittrich and Duysters 2007; Chesbrough and Prencipe 2008; Hannelize 2013).

It becomes therefore urgent, in this context, to grasp more comprehensively how partnerships for innovation work and try to identify possible patterns according to each sector and group of countries.

\section{Partners for Cooperation and Innovative Performance}

Choosing the right cooperation partner closes a trade-off between gains and expected risks (Powell et al. 1996; Katila et al. 2008). A partner's characteristics may affect the firm's process of innovation management (Whitley 2002). With regard to partnerships for cooperation with external partners, many studies were performed but the results are not always consensual. Atallah (2002) analyzes the innovation performance considering the results of $R \& D$ and concludes that there is influence of the partner type in the results obtained.

The same study indicates that innovation performance is positively influenced by vertical externalities, especially suppliers and customers, instead of horizontal spillovers such as universities, research centers, and competitors. 
Regarding internal cooperation, that is, within the firm or firms within the same group, some studies admit that this type of cooperation, particularly interdepartmental can favor marketing, R\&D (Troy et al. 2008; Jansen et al. 2009) and innovation (De Luca and Atuahene-Gima 2007; Troy et al. 2008).

Freel and Harrison (2006) found empirical evidence that product innovations are positively influenced by partnerships with customers and public sector institutions, while process innovations are promoted through cooperation with suppliers and universities.

Belderbos et al. (2004), in an empirical study applied to Dutch firms, conclude that the increase in labor productivity is related to cooperation activities with suppliers and competitors and that the increase in new product sales is allied to the cooperation with universities, research centers, and competitors.

The study developed by Trigo and Vence (2012) states that, on the one hand, firms with innovative activities linked to technology tend to cooperate more with suppliers, universities, and R\&D institutes. On the other hand, cooperation with consultants, commercial laboratories, and R\&D private institutes is more valued in activities with low innovation capacity, where the propensity for innovation is also reduced (Trigo and Vence 2012).

Another study by Siedschlag et al. (2012) states that the cooperation with suppliers, consultants, laboratories, R\&D institutes, universities, and other higher education institutions is positively associated with the results of innovation.

Research on the relationship between the type of cooperation partner and the innovative performance, measured in terms of increased product innovation or process does not show clear results; it provides, however, a glimpse of some propensities.

Cooperation with customers and suppliers provides knowledge about technology and about markets (Whitley 2002), reduces the time-to-market (Liker et al. 1999), and favors product and process innovations.

Cooperation with customers allows firms to collect more market-related information (Fritsch and Lukas 2001) and participation in R\&D teams (Atuahene-Gima 1995) thus enhancing product innovation.

Cooperation with suppliers may reduce time-to-market and risk, increase the flexibility and quality of products and favors the firm's adaptability to the market (Chung and Kim 2003).

With regard to cooperation activities with competitors, it is understood that it will be more beneficial for both parties if the problems and/or common shares are beyond the competitive sphere (Tether 2002).

It is recognized that more knowledge can be achieved when firms cooperate with a market rival, a foreign firm or one that operates in the areas of new technologies, when compared to the firm itself. From this perspective, collaboration with a competitor may actually improve a firm's base of knowledge, as rival businesses often have similar needs regarding the development of products and processes. Several empirical studies confirm that cooperating with competitors increases the firms' innovative capacity or performance (Belderbos et al. 2004; Aschhoff and Schmidt 2008). In this context, one meets the term "co-opetition," which will be used with the expression cooperative competition, based on the idea of a dynamic interaction between cooperation and competition (Lado et al. 1997; Gnyawali et al. 2006; Chen 2008) and assumed as the only strategy that capitalizes cooperation and competition benefits (Bengtsson and Kock 2000). 
Cooperating with research centers provides access to technological knowledge (Drejer and Jorgensen 2005) and plays an important role in technological innovation (Vuola and Hameri 2006) as well as in the opening of new markets (Belderbos et al. 2004).

The benefits of cooperation activities for innovation improve if the external partner is able to complement, in terms of features and capabilities, the firm's own resources (Beck and Schenker-Wicki 2013). However, these benefits must be weighed taking into account transaction costs (Pisano 1990) generated to coordinate, manage, and control the activities of the partners involved (Nieto and Santamaria 2007). Assets' specificity, the asymmetric information, the opportunistic behavior of the partners involved and the uncertainty about the appropriateness of the innovation returns are important factors associated with these costs (Beck and Schenker-Wicki 2013).

Several authors highlighted the differences between services and manufacturing sector concerning innovation (Djellal and Gallouj 1999; Hollenstein 2003; Cainelli et al. 2006; Pires et al. 2008). In general, the researches point out that innovation activities in services differ from manufacturing to some extent although not completely. But this differences could justify compare these two sectors in order to confirm or not eventual differences in the patterns of cooperation for innovation in Europe.

In short, one may conclude that there are different perspectives and the various studies differ in terms of the type of cooperation partners for innovation. However, a common evidence appears in a number of studies: we have two types of internal partners (within the firm or group) and external (this specific set of partnerships comprises several agents or entities, such as suppliers, competitors, customers, R\&D institutes, universities, etc.). These can generate benefits or not and that will depend on several factors.

The literature review allowed the establishment of the following assumptions:

H.1: Cooperation for innovation with external partners differs, in Europe, between manufacturing and services.

H.1.a.: Cooperation for innovation with suppliers, consultants, commercial laboratories and private institutes $R \& D$ differs, in Europe, between manufacturing and services.

H.1.b.: Cooperation for innovation with clients or consumers differs, in Europe, between manufacturing and services.

H.1.c.: Cooperation for innovation with competitors or firms from the same sector, in Europe, between manufacturing and services.

H.1.d.: Cooperation for innovation with universities or other higher education institutions, government or public research institutes differs, in Europe, between manufacturing and services.

H.1.e.: Cooperation for innovation with other external sources of information and cooperation differs, in Europe, between manufacturing and services.

H.2: Cooperation for innovation with internal partners differs, in Europe, between manufacturing and services.

\section{Methodology}

This study was based on the Community Innovation Survey (CIS micro-data) provided by EUROSTAT. The members of the European Union collect the questionnaires every 
2 years, usually. The data compilation is voluntary and, for that reason, is represented, in micro-data, according to the years of its release by different countries.

CIS may be described as a questionnaire that collects data on firms' entrepreneurial activity considering a variety of information, such as innovation by sector and type of business, different types of innovation, aspects related to the development of innovative processes, financing expenses with innovation, cooperation for innovation, among others.

\section{Data Analysis and Discussion of the Results}

This study analyzes the cooperation for innovation, using, for this purpose, the variables related to information sources for innovation included in the micro-data CIS 2008 (Table 1) for the 15 European countries included in the database in this period of time. Table 1 displays the variables related to cooperation used in this empirical study.

Table 2 displays the countries included in the study and the respective identifying acronyms.

For the analysis of data and based on the requirements of the literature review, the database was divided according to the activity sector of manufacturing and services (assorted according to the NACE).

\section{Descriptive Analysis}

The results presented in Table 3 display the percentage distribution of firms according to the sources of information. The variables are measured based on a scale ranging from zero (not used) 1 (little use), 2 (used regularly) to 3 (often used), according to the type and intensity with which they cooperate to innovate.

The table therefore presents the average per variable and per country, as well as the standard deviation in parentheses and provides evidence that, in average, cooperation values are very low, with values above 2 not existing in either variable

Table 1 Description of cooperation variables

\begin{tabular}{ll}
\hline Variables & Description of cooperation variables \\
\hline SENTG & Other enterprises within your enterprise group \\
SSUP & Suppliers of equipment, materials, components, or software \\
SCLI & Clients or customers \\
SCOM & Competitors or other enterprises in your sector \\
SINS & Consultants, commercial labs, or private R\&D institutes \\
SUNI & Universities or other higher education institutions \\
SGMT & Government or public research institutes \\
SCON & Conferences, trade fairs, exhibitions \\
SJOU & Scientific journals and trade/technical publications \\
SPRO & Professional and industry associations \\
\hline
\end{tabular}


Table 2 Observations by country-CIS Micro-data 2008

\begin{tabular}{lll}
\hline Abbreviation & Country & Observations \\
\hline CY & Cyprus & 1024 \\
CZ & Czech Republic & 6800 \\
DE & Germany & 6028 \\
EE & Estonia & 3987 \\
ES & Spain & 37,401 \\
HU & Hungary & 5390 \\
IE & Ireland & 2178 \\
IT & Italy & 19,904 \\
LT & Lithuania & 2111 \\
LV & Latvia & 1077 \\
NO & Norway & 4884 \\
PT & Portugal & 6512 \\
RO & Romania & 9631 \\
SI & Slovenia & 2593 \\
SK & Slovakia & 2297 \\
\hline
\end{tabular}

or country, with a use rate estimated between the "little" and the "regularly." The table also reveals that variables SENTG and SSUP, respectively, cooperation within enterprises and within enterprise group and suppliers of equipments, materials, components and software, present higher averages than the other variables.

\section{Factor Analysis}

Given the size of the database and the objectives of the investigation, it was considered that it would be appropriate to apply the factor analysis method. This is a multivariate statistical procedure that allows the simplification of information. It is generally used to represent the relationships between a set of variables through a smaller number of features, originating common factors. This type of multivariate data analysis may reduce the initial number of variables, recognizing the common underlying factors and even deleting information regarded as redundant and safeguarding the minimum loss of information.

This technique was used as it was considered suitable, whether from an exploratory point of view or from a confirmatory perspective (Hair et al. 1998). To be noted that of the objectives of this research involves the study of partnerships in terms of cooperation for innovation in manufacturing and services in Europe. For each variable J, the model used may be described as follows:

$$
X j=b j_{1} F_{1}+b j_{2} F_{2}+\ldots+b j_{K} F_{K}+U_{j}
$$

where

$F_{1}, F_{2}, \ldots, F_{K} \quad$ are the common factors 
Table 3 Descriptive statistics to cooperative variables by country

\begin{tabular}{|c|c|c|c|c|c|c|c|c|c|c|}
\hline \multirow[t]{2}{*}{ Country } & \multicolumn{10}{|l|}{ Variables } \\
\hline & SENTG & SSUP & SCLI & SCOM & SINS & SUNI & SGMT & SCON & SJOU & SPRO \\
\hline \multirow[t]{2}{*}{$\mathrm{CY}$} & 1.37 & 1.22 & 0.91 & 0.69 & 1.03 & 0.67 & 0.63 & 0.99 & 0.78 & 0.65 \\
\hline & $(0.90)$ & $(1.17)$ & $(0.91)$ & $(1.00)$ & $(0.96)$ & $(0.73)$ & $(0.85)$ & $(0.87)$ & $(0.90)$ & $(0.86)$ \\
\hline \multirow[t]{2}{*}{$\mathrm{CZ}$} & 1.03 & 0.76 & 0.80 & 1.29 & 0.55 & 0.57 & 0.37 & 1.11 & 0.95 & 0.55 \\
\hline & $(0.91)$ & $(1.19)$ & $(1.18)$ & $(1.06)$ & $(0.88)$ & $(0.99)$ & $(0.80)$ & $(1.10)$ & (1.08) & $(0.96)$ \\
\hline \multirow[t]{2}{*}{$\mathrm{DE}$} & 1.36 & 0.83 & 0.80 & 1.12 & 0.62 & 0.46 & 0.37 & 1.09 & 1.11 & 0.63 \\
\hline & $(0.90)$ & $(1.04)$ & $(0.96)$ & $(1.01)$ & $(1.01)$ & $(0.91)$ & $(0.68)$ & $(0.93)$ & (0.99) & (0.94) \\
\hline \multirow[t]{2}{*}{$\mathrm{EE}$} & 1.11 & 0.99 & 0.88 & 0.73 & 0.40 & 0.33 & 0.12 & 0.94 & 0.50 & 0.55 \\
\hline & $(0.92)$ & $(1.02)$ & $(1.11)$ & $(1.01)$ & $(0.76)$ & $(0.74)$ & $(0.59)$ & (1.11) & (0.97) & (0.87) \\
\hline \multirow[t]{2}{*}{ ES } & 0.91 & 1.03 & 0.76 & 0.46 & 0.53 & 0.55 & 0.31 & 0.75 & 0.86 & 0.32 \\
\hline & (1.09) & $(1.01)$ & (1.03) & $(0.97)$ & (1.02) & $(0.95)$ & $(0.79)$ & $(0.94)$ & $(0.90)$ & $(0.91)$ \\
\hline \multirow[t]{2}{*}{$\mathrm{HU}$} & 1.07 & 1.37 & 1.11 & 1.32 & 0.99 & 0.56 & 0.32 & 1.26 & 1.21 & 0.97 \\
\hline & $(0.97)$ & $(0.99)$ & $(1.12)$ & $(1.02)$ & $(1.00)$ & $(0.89)$ & $(0.67)$ & $(0.93)$ & $(0.96)$ & $(0.91)$ \\
\hline \multirow[t]{2}{*}{ IE } & 1.43 & 1.72 & 0.98 & 1.33 & 1.00 & 0.68 & 0.31 & 1.29 & 1.03 & 0.88 \\
\hline & $(0.97)$ & $(1.02)$ & $(1.15)$ & $(1.01)$ & $(0.99)$ & $(0.96)$ & $(0.64)$ & $(0.93)$ & $(0.87)$ & (0.94) \\
\hline \multirow[t]{2}{*}{ IT } & 1.83 & 1.54 & 0.88 & 0.88 & 1.03 & 0.32 & 0.23 & 0.97 & 1.19 & 0.93 \\
\hline & $(1.01)$ & $(1.04)$ & $(1.02)$ & $(1.06)$ & $(1.00)$ & $(0.74)$ & $(0.62)$ & $(0.95)$ & $(0.88)$ & (1.01) \\
\hline \multirow[t]{2}{*}{ LT } & 1.76 & 1.35 & 1.14 & 1.34 & 0.85 & 0.33 & 0.23 & 1.07 & 1.04 & 0.66 \\
\hline & (1.07) & $(1.02)$ & $(1.01)$ & (1.09) & (1.01) & $(0.82)$ & $(0.64)$ & $(1.05)$ & (0.97) & $(0.93)$ \\
\hline \multirow[t]{2}{*}{ LV } & 1.58 & 1.21 & 1.33 & 1.35 & 0.77 & 0.40 & 0.43 & 0.93 & 1.02 & 0.62 \\
\hline & $(1.02)$ & $(0.93)$ & $(1.08)$ & $(1.14)$ & $(0.95)$ & $(0.73)$ & $(0.72)$ & $(0.93)$ & (1.00) & $(0.87)$ \\
\hline \multirow[t]{2}{*}{ NO } & 1.73 & 1.31 & 1.06 & 0.92 & 1.01 & 0.34 & 0.33 & 1.34 & 0.95 & 0.76 \\
\hline & $(0.95)$ & $(1.04)$ & $(1.01)$ & $(0.92)$ & $(0.99)$ & $(0.89)$ & $(0.93)$ & $(0.88)$ & $(0.92)$ & $(0.96)$ \\
\hline \multirow[t]{2}{*}{ PT } & 1.18 & 1.04 & 1.08 & 0.77 & 0.56 & 0.37 & 0.29 & 0.81 & 0.73 & 0.62 \\
\hline & $(0.78)$ & $(0.82)$ & $(0.93)$ & $(1.17)$ & $(0.92)$ & $(0.89)$ & (1.09) & $(1.01)$ & $(0.93)$ & (1.02) \\
\hline \multirow[t]{2}{*}{ RO } & 1.23 & 1.08 & 1.14 & 1.30 & 0.43 & 0.55 & 0.44 & 0.91 & 1.02 & 0.96 \\
\hline & $(0.98)$ & $(1.04)$ & $(0.91)$ & $(1.11)$ & $(0.94)$ & $(0.91)$ & $(0.93)$ & $(0.91)$ & $(0.93)$ & $(0.84)$ \\
\hline \multirow[t]{2}{*}{ SI } & 1.79 & 1.71 & 1.83 & 1.33 & 0.84 & 0.86 & 0.65 & 0.70 & 0.95 & 0.79 \\
\hline & $(1.04)$ & $(1.03)$ & $(1.13)$ & $(1.01)$ & $(0.74)$ & $(0.88)$ & $(0.93)$ & $(0.96)$ & (1.01) & (0.99) \\
\hline \multirow[t]{2}{*}{ SK } & 1.09 & 1.45 & 1.12 & 0.95 & 0.75 & 0.53 & 0.65 & 0.93 & 0.95 & 0.99 \\
\hline & $(0.99)$ & $(1.01)$ & $(0.93)$ & $(1.15)$ & $(0.88)$ & $(0.73)$ & $(0.91)$ & $(1.00)$ & (1.05) & $(0.89)$ \\
\hline
\end{tabular}
$b j_{1}, \ldots, b j_{K}$
are the factor loadings
$U_{j} \quad$ is the residual factor

The principal component analysis (PCA) was used to estimate the weights of the factors (loadings) and the commonalities of factors. This method transforms a number of correlated variables into a smaller set of independent variables, linear combinations of the first (the main components) and allows a significant reduction of the data complexity which will rule out the factors with an eigenvalue < 1. An orthogonal Varimax rotation was applied, as this rotation seeks to minimize the number of variables with high values regarding the weights associated 
with a certain common factor, i.e., makes the weighting factors become close to 0 or 1 .

The weights of factors over an absolute value of 0.6 were considered relevant to the interpretation of the data. As a first stage, the Kaiser-Meyer-Olkin (KMO) test was performed, in order to test the technical application of this methodology, achieving a value considered good $(0.82)$ and confirm the sampling adequacy.

\section{Presentation and Discussion of Results}

The presentation of results groups the factors related to each of the groups of firms according to sectors, namely manufacturing and services. The extraction of segments from the main components allowed, in addition, the identification of commonalities referring to the variance estimates that each variable has in common with each factor. Table 4 provides this information concerning manufacturing and services.

We begin by analyzing the results for the manufacturing sector in Table 4. Factor 1, for manufacturing, groups cooperation sources of institutional or professional character, strongly related to the core business sector, having this factor been named as "Institutional and Professional Cooperation."

Within the partners for cooperation identified, several studies establish the importance of public and government institutes, as well as of universities and research centers for innovation in the industrial sector (Becker and Peters 2000; Becker and Dietz 2004).

Factor 2 assembles a set of variables related, on the one hand, to competitors and other firms in the sector, revealing that, possibly, from a strategic point of view, the European industrial firms develop cooperative competition.

The remaining variables, grouped, in this factor, for manufacturing, concern other sources of associated external cooperation that can be connected to external collaborative networks namely at conferences, fairs and such, suppliers of equipment and materials; they also regard information accessed through scientific and commercial journals, among other technical publications. This was referred to as "Corporate Competition and Networks." Table 5 presents the variables grouped in factor 2, for manufacturing. Some studies point to the role of vertical cooperation for the development of innovation in the manufacturing field (Koschatzky 1999; Fischer and Varga 2002). This factor also highlights the concept of cooperative

Table 4 Factor 1 to manufacturing in Europe: institutional and professional cooperation

\begin{tabular}{lc}
\hline Variables & Loadings \\
\hline Government or public research institutes [SGMT] & 0.96 \\
Universities or other higher education institutions [SUNI] & 0.87 \\
Professional and industry associations [SPRO] & 086 \\
Consultants, commercial labs, or private R\&D institutes [SINS] & 0.85 \\
Eigenvalue $=3.8$ & \\
Explained variance $=38.02 \%$ &
\end{tabular}


Table 5 Factor 2 to manufacturing in Europe: corporate competition and networks

Eigenvalue $=3.25$

Explained variance $=32.50 \%$

competition, assumed as a way to draw benefits from cooperation and competition (Lado et al. 1997; Bengtsson and Kock 2000; Gnyawali et al. 2006; Chen 2008).

Table 6 displays factor 3 to manufacturing. It gathers variables inherent to cooperation sources in the internal domain (as in cooperation within the firm) and the market (customers and consumers). This factor was named "Internal Cooperation and with the Market". Several authors (Miotti and Sachwald 2003) state that cooperation helps to unlock internal constraints to innovation by facilitating the access to external sources of knowledge and allowing firms to benefit from work division in the innovation process.

The following tables refer to the extraction of components and assembly of covariables for the service sector. Table 7 shows factor 1 to services, immediately revealing significant differences from the first factor, extracted to cooperation in European firms.

In this case, the factor with the greatest explained variance comprises variables associated with networks for external contacts, namely conferences and fairs and access to scientific journals and other publications; cooperative competition, including competitors and other firms in the sector (these variables were grouped in factor 2 in manufacturing) and also customers.

Factor 1 in services apparently groups more diverse collaboration sources, which is justified by the influence of the market and the external environment in this sector, particularly in the case of some groups of services such as KIBS (Knowledge Intensive Business Services). In services, customers, competitors, and other external sources are considered relevant to the introduction of new services, as well as to the essential learning innovative performance, orientation towards the customer and joint cooperation (with customers) in the innovation process are identified as particularly relevant (Jiménez-Zarco et al. 2011).

Table 6 Factor 3 to manufacturing in Europe: internal cooperation and with the market

\begin{tabular}{lc}
\hline Variables & Loadings \\
\hline Other enterprises within your enterprise group [SENTG] & 0.96 \\
Clients or customers [SCLI] & 0.60 \\
Eigenvalue $=1.99$ & \\
Explained variance $=19.93 \%$ & \\
\hline
\end{tabular}


Table 7 Factor 1 to services in Europe: competitive cooperation, networks, and market

\begin{tabular}{lc} 
Variables & Loadings \\
\hline Conferences, trade fairs, exhibitions $[\mathrm{SCON}]$ & 0.85 \\
Competitors or other enterprises in your sector $[\mathrm{SCOM}]$ & 0.84 \\
Clients or customers [SCLI] & 0.75 \\
Scientific journals and trade/technical publications [SJOU] & 0.74 \\
Eigenvalue $=3.70$ & \\
Explained variance $=37.01 \%$ & \\
\hline
\end{tabular}

The research developed by Trigo and Vence (2012) also points towards, in the case of services, cooperation with customers as being crucial, referring, as well, to its relevance in commercial activities, such as transportation support activities, travel agencies, final intermediation and also on radio and television.

Factor 2 for services corresponds to factor 1 to the manufacturing and refers to sources of cooperation of institutional or professional nature, strongly related to the core business, having been named "Institutional and professional cooperation." Although one cannot generalize, services in general are less associated with technology; some studies (Trigo and Vence 2012) suggest that cooperation with consultants, commercial laboratories and $\mathrm{R} \& \mathrm{D}$ institutes in the private sector are more valued in activities with this profile (Table 8).

Table 9 presents factor 3 for the European services. This brings together two items, one on the internal cooperation within the firm or the business group and the other on cooperation with the supply chain of suppliers of diverse equipment.

It is noted, at this point, yet another difference regarding manufacturing, as in services the variable SSUP appears in factor 3, while in manufacturing that place was taken by cooperation with customers (SCLI).

This difference reveals a greater involvement of the service sector with the market, which can be justified by the characteristics of intangibility, no-storage and coproduction that services reveal. Given the above, it was decided to name this factor "Internal Cooperation and with the Supply Chain." In the case of KIBS (Knowledge Intensive Business Services), other studies show the relevance of vertical cooperation in the supply chain with suppliers (Koschatzky 1999).

Table 8 Factor 2 to services in Europe: institutional and professional cooperation

\begin{tabular}{lc}
\hline Variables & Loadings \\
\hline Professional and industry associations [SPRO] & 0.89 \\
Consultants, commercial labs, or private R\&D institutes [SINS] & 0.87 \\
Universities or other higher education institutions [SUNI] & 0.75 \\
Government or public research institutes [SGMT] & 0.69 \\
Eigenvalue $=3.14$ & \\
Explained variance $=31.41 \%$ &
\end{tabular}


Table 9 Factor 3 to services in Europe: internal cooperation and with supply chain

\begin{tabular}{lc} 
Variables & Loadings \\
\hline Other enterprises within your enterprise group [SENTG] & 0.91 \\
Suppliers of equipment, materials, components, or software [SSUP] & 0.87 \\
Eigenvalue $=1.89$ & \\
Explained variable $=18.91 \%$ &
\end{tabular}

In the following section, we seek, based on factors identified for each sector, to undertake its crossing in order to better understand the location of each country in order to predict the possibility of pattern visualization.

\section{Summary of the Results of the Hypothesis}

The empirical study presented was anchored in a set of theoretical considerations that allowed the extraction of hypotheses that were tested through empirical study. The discussion of the results allowed the validation of such hypotheses. It was found that there are differences in terms of grouping the variables, being H.2 the only case where the same variable groups in the same factor order (Cooperation for innovation with internal partners differs, in Europe, between manufacturing and services), which, in both cases, although with different types of grouping, appears in factor 3 , a fact that led us to reject this hypothesis. Table 10 presents the validation of hypotheses.

Table 10 Validation of hypotheses

Hypotheses

Validation

H.1: Cooperation for innovation with external partners differs, in Europe, between manufacturing Yes and services.

H.1.a.: Cooperation for innovation with suppliers, consultants, commercial laboratories and Yes private institutes $R \& D$ differs, in Europe, between manufacturing and services.

H.1.b.: Cooperation for innovation with clients or consumers differs, in Europe, between Yes manufacturing and services.

H.1.c.: Cooperation for innovation with competitors or firms from the same sector, in Europe, Yes between manufacturing and services.

H.1.d.: Cooperation for innovation with universities or other higher education institutions, Yes government or public research institutes differs, in Europe, between manufacturing and services.

H.1.e.: Cooperation for innovation with other external sources of information and cooperation Yes differs, in Europe, between manufacturing and services.

H.2: Cooperation for innovation with internal partners differs, in Europe, between manufacturing No and services. 


\section{An Outlook of the Cooperation for Innovation in Europe}

This research seeks, in addition, to understand whether it is possible or not, to identify eventual patterns of cooperation for innovation in European countries from the factors identified in the previous statistical analysis. In this sense, we proceeded to the compare factor 1 (Institutional and Professional Cooperation) with factor 2 (Cooperative Competition and Networks), both with explained variances above $30 \%$ for the two sectors.

Graphically, this analysis ranks the countries taking into account the scores of the factors.

Figure 1 can be perceived as a conceptual model of the manufacturing, as it helps to understand the position of the countries into four quadrants. Thus, according to the signal assumed by the scores of factors, those quadrants were classified as:

- Strong cooperation (1st quadrant): it assumes positive values for both factors;

- Inter-network cooperation (2nd quadrant): It assumes positive values for factor 2, related to cooperative competition and networks and negative values for factor 1 , related to institutional and professional cooperation;

- Weak cooperation (3rd quadrant): both factors assume values below 1;

- Institutional cooperation (4th Quadrant): It assumes positive values for factor 1, related to institutional and professional cooperation and negative values for factor 2 .

Figure 1 presents the conceptual model extracted from the empirical study which will act as the base from which the European countries will be positioned in manufacturing.

Figure 2 positions countries in four quadrants.

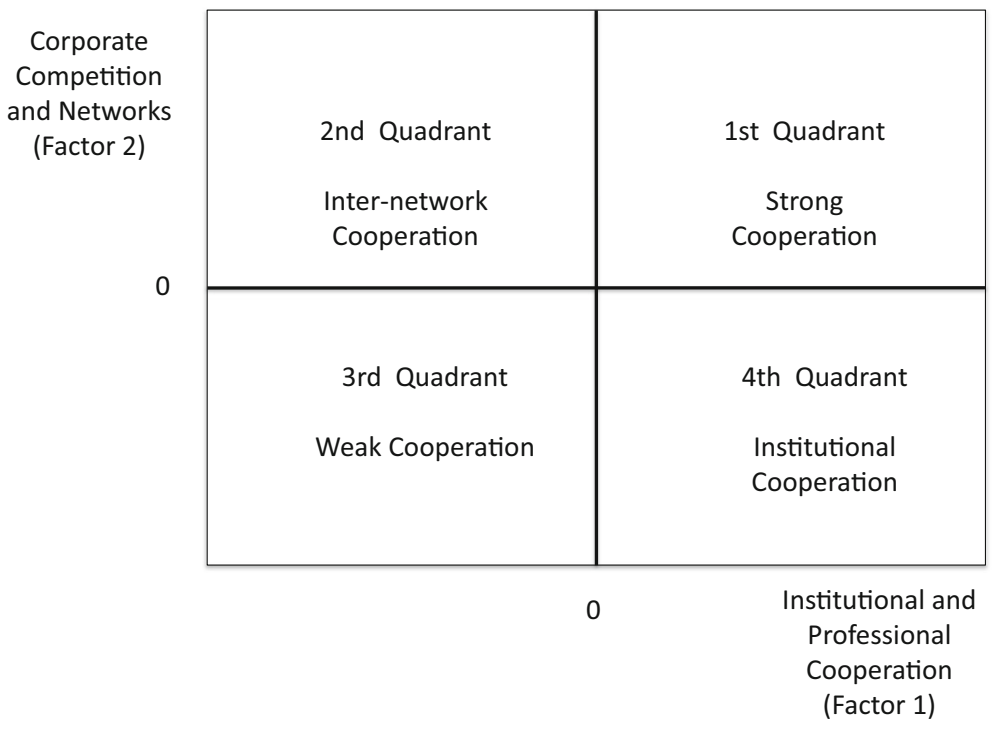

Fig. 1 Conceptual model for innovation cooperation in manufacturing in Europe 


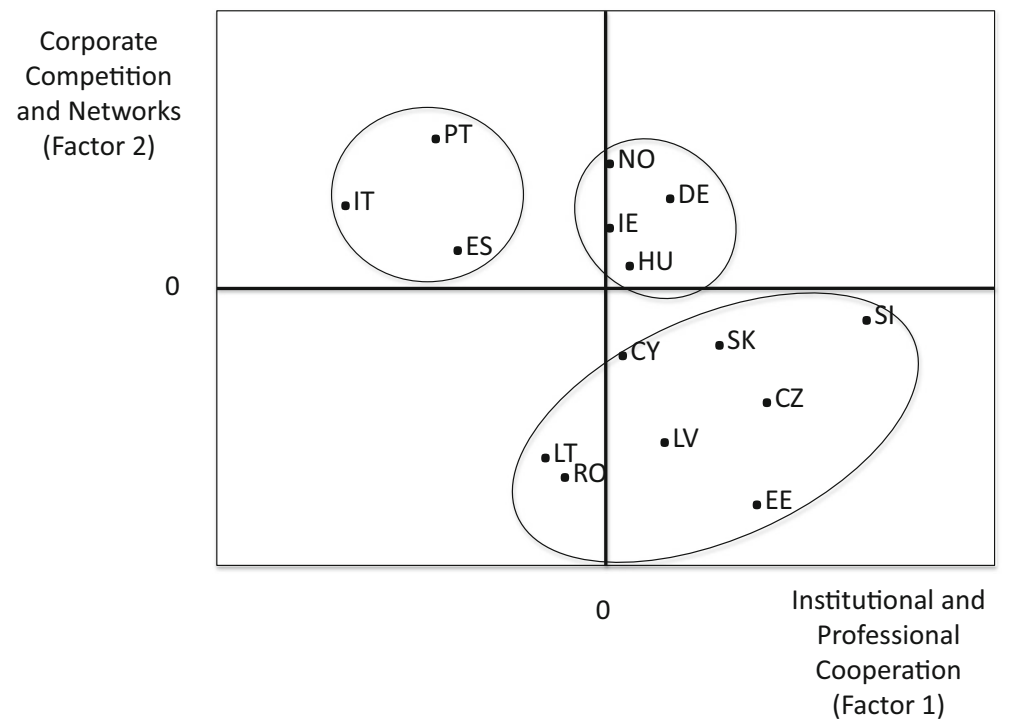

Fig. 2 Cooperation in manufacturing by country

The analysis of this figure allows us to identify some patterns of cooperation for innovation in this period. To facilitate the analysis those countries were graphically highlighted according to groups that suggest proximity. We can thus distinguish three large groups, although within them there are also some subgroups to be noted. We may therefore identify, according to the quadrants:

- The 1st quadrant, regarding strong cooperation, comprising Norway, Ireland, Germany and Hungary, although the latter presents values close to zero. To be noted that this group comprises mostly countries with strong, competitive industries and the results may be associated with these aspects;

- The 2nd quadrant, referring to the Inter-network cooperation, comprises Portugal, Italy and Spain, all geographically located in southern Europe. This result seemed interesting, as it appears to mean that these countries use more networks of a less formal nature, which can meet their economic structures and cultural foundations;

- 3 rd and 4th quadrants, related to weak and constitutional cooperation, comprise most of the countries under evaluation. This group consists of Eastern European countries that joined the European Union more recently, which may reveal that the economic structures of these countries have similarities that inhibit private cooperation, the collaborative competition and networks type and reward a more formal and institutional cooperation, suggesting that there could still be an influence of the central leadership structures in these economies that have been developing the process of transition to a market economy over the past 20 years.

Figure 3 may be regarded as a conceptual model for services as it allows a better understanding of the positioning of countries in the four quadrants. Thus, according to the signal given by the scores of factors, those quadrants were classified as: 
- Strong cooperation (1st quadrant): it assumes positive values for both factors;

- Institutional cooperation (2nd quadrant): it assumes positive values for factor 2, related to institutional and professional cooperation and negative values for factor 1 ;

- Weak cooperation (3rd quadrant): both factors assume values below 1;

- Cooperative competition, market and networks (4th quadrant): it assumes positive values for factor 1 , related to cooperative competition, market and networks and negative values for factor 2, related to institutional and professional cooperation;

Figure 3 presents the conceptual model extracted from the empirical study which will act as the base from which the European countries will be positioned in services.

Figure 4 positions the countries under evaluation in four quadrants. The analysis of this figure suggests some considerations. To facilitate the analysis, countries are pointed out graphically according to the groups that suggest proximity. One can therefore visualize three groups being, in the case of services, the arrangement of countries more dispersed than in manufacturing. One may, according to those quadrants, identify:

- In the 2nd quadrant, referring to institutional cooperation, we have Hungary, Cyprus, Czech Republic, Lithuania, Romania, Estonia, and Slovakia, a result that meets the previously referenced to the manufacturing's case for most countries marked with the exception of Hungary, suggesting that the pattern based on formal and institutional sources remains in the service sector

- The 3rd quadrant, weak cooperation, groups Italy and Spain, with weaker values and, at some distance, a second group containing Portugal and Ireland. In this case, the positioning of countries is somewhat different to that seen in manufacturing, Ireland being closer to countries in the South and Portugal distancing itself from

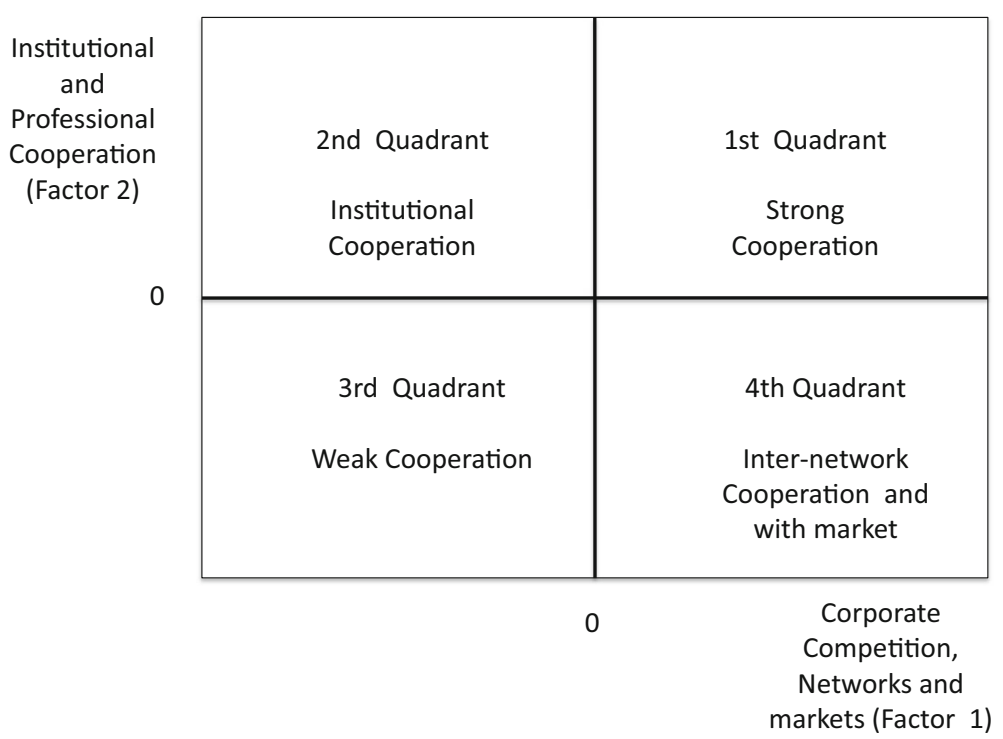

Fig. 3 Conceptual model for innovation cooperation in services in Europe 


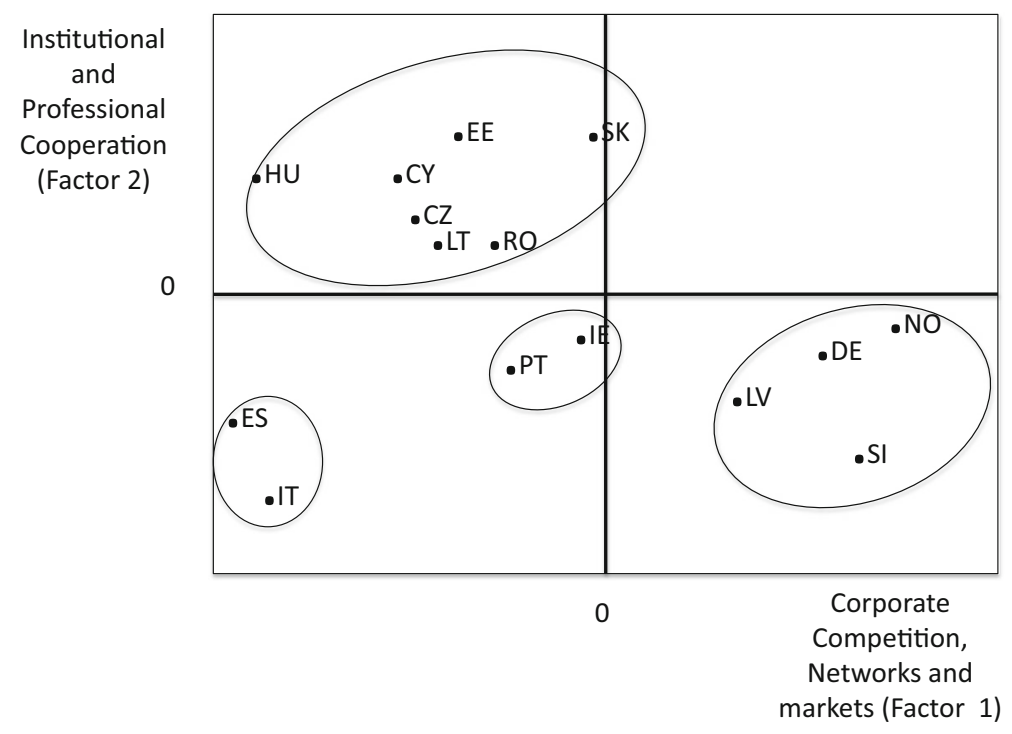

Fig. 4 Cooperation in services by country

Spain and Italy. The pattern, however, is similar among the four countries and determined by a weaker cooperation;

- The 4th quadrant, concerning cooperative competition, networks and markets, comprises the remaining four countries: Germany, Norway, Latvia, and Slovenia. This group also reveals differences compared to that seen in the case of manufacturing, as Latvia and Slovenia distance themselves from the Eastern countries, which may be related to the characteristics of this sector, in these countries - this issue will not be explored in greater detail as it is not a central element in terms of the objectives of this research.

This analysis suggests the existence of differences and standards in terms of cooperation for innovation in Europe, meeting the few studies that address this topic resourcing to empirical studies.

\section{Final Remarks}

The results of the empirical study allow us to make some considerations on cooperation for innovation and types of partners in Europe. First, the descriptive analysis of the data shows low averages with regard to cooperation for innovation in the ten variables used for cooperation partners for innovation. These results suggest that, in general, European firms are not accustomed to cooperate.

Second, manufacturing and services display obvious differences, in terms of partners. Manufacturing is presented in three groups - the first refers to the institutional and professional cooperation, the second to the cooperative and competitive networks, and the third to internal cooperation and the market. Services, on the other hand, include, in 
the first group, cooperative competition, networks and market, in the second group institutional and professional cooperation and, in the third group, internal cooperation and cooperation with the supply chain.

The grouping of variables has only one point in common, which refers to the fact that internal cooperation appears, in both sectors, grouped in factor 3, a fact that led us to reject the hypothesis "Cooperation for innovation with internal partners differs, in Europe, between manufacturing and services."

As regards the positioning of the countries under analysis and according to the quadrants that were defined based on the factors with the greatest variance explained (1 and 2) for each sector, the results are interesting and suggest patterns of cooperation for innovation in Europe which once again differ between the two sectors.

To be noted that most countries where comprised in the so-called 1st quadrant of cooperation, stronger in the case of manufacturing than in services, where this quadrant is virtually depopulated.

It is also important to note that, in most cases, countries were grouped according to some commonalities, such as geographic location, productive structure, the type of economy, entrepreneurial culture among others, allowing to envision cooperation patterns based in dynamics of geopolitical nature. Other studies provide similar conclusions and suggest differences in cooperation patterns in Europe based on geography, productive structure and type of economy, such as Arvanitis and Bolli (2013) that used CIS3 data from five countries and namely Belgium, Germany, Norway, Portugal, and Switzerland, but despite their apparent heterogeneity, they concluded that the main results on firm-level factor affecting the propensity to innovation cooperation hold across the investigated countries.

It also interesting to note that countries appear grouped in the quadrants almost according to the development levels, such as Southern Europe, Eastern Europe ("new members"), and Central Europe. Others studies reveal similar result. Srholec (2015) argued that Southern European countries have been expressed as having fragile innovation systems; though, this has been recognized to be even more the case for new EU members. Also Paasi (1998) argued innovation systems in transition countries to be relatively less efficient than in market economies.

In short, the scientific results of this paper may be useful in the design of public policies to encourage cooperation for innovation in Europe, and highlight to the risk of designing centrally public policies similar to all countries could fail due the inadequacy to the entrepreneurial culture and economic systems. In general Southern Countries for cultural reasons and Eastern Countries due their more recent transition to a market economy reveal higher levels of bureaucracy and commercial trust must be assigned in a contract. Central Europe and mainly Nordic Countries reveal a different entrepreneurial culture more assigned in the confidence. These cultural differences reflect on the cooperation and in the capability of the firms establish networks to develop new products or services, and the patterns identified in this papers mirror this tendency and the distinctive ways as entrepreneurs are related with government, universities, suppliers, clients etc. Nevertheless even in southern European countries start-ups and young entrepreneurs become more cooperative and are influenced by those they regard as their peers. Attending to the managerial implications, this research suggest that cooperation could be improved in Europe, and the active engagement of the firms to cooperate could be influenced by culture and direct experience in a start-up 
environment. And a strategy to reinforce cooperation could be internship programs, employment opportunities or partnership programs between firms and industry (World Economic Forum 2014).

So, European public policies must shape this particularities and H2020 strategy could be an interesting tool to develop suitable regional public policies to improve cooperation for innovation.

A major limitation of this study that needs to be acknowledged is that the data reveal only whether a firm cooperated or not. And if cooperate the level of cooperation with different patterns, but we do not have evidences about the firms' motives for cooperation on innovation using more detailed evidence about these deals, as reported by the firms directly. Another limitation given by the data not include all European countries.

Future investigations mean to apply this study to the most recent data and try to understand whether the grouping of countries according to their stage of innovation provides different results, as to complement this analysis.

Acknowledgements The first author is pleased to acknowledge financial support from Fundação para a Ciência e a Tecnologia (grant UID/ECO/04007/2013) and FEDER/COMPETE (POCI-01-0145-FEDER-007659).

\section{References}

Arvanitis, S. (2012). How do different motives for R\&D cooperation affect firm performance? An analysis based on Swiss micro data. Journal of Evolutionary Economics, 22(5), 981-1007.

Arvanitis, S., \& Bolli, T. (2013). A comparison of national and international innovation cooperation in five European countries. Review of Industrial Organization, 43(3), 163-191.

Aschhoff, B., \& Schmidt, T. (2008). Empirical evidence on the success of R\&D cooperation - happy together? Review of Industrial Organization, 33(1), 41-62.

Atallah, G. (2002). Vertical R\&D spillovers, cooperation, market structure, and innovation. Economics of Innovattion and New Technology, 11, 179-209.

Atuahene-Gima, K. (1995). An exploratory analysis of the impact of market orientation on new product performance - a contingency approach. Journal of Product Innovation Management, 12(4), 275-293.

Beck, M., \& Schenker-Wicki, A. (2013). Cooperating with external partners: the importance of diversity for innovation performance. Working Paper No. 331, UZH Business Working Paper Series, University of Zurick, available on http:/www.business.uzh.ch/forschung/wps.html

Becker, W., \& Dietz, J. (2004). R\&D cooperation and innovation activities of firms - evidence for the German manufacturing industry. Research Policy, 33, 209-223.

Becker, W., \& Peters, J. (2000). University knowledge and innovation activities. In P. Saviotti, \& B. Nooteboom (Eds.), Technology and knowledge: from the firm to innovation systems (pp. 80-117). Northampton: Cheltenham.

Belderbos, R., Carree, M., Diederen, B., Lokshin, B., \& Veugelers, R. (2004). Heterogeneity in R\&D cooperation strategies. International Journal of Industrial Organization, 22(8), 1237-1263.

Belderbos, R., Carree, M., \& Lokshin, B. (2006). Complementarity in R\&D cooperation strategies. Review of Industrial Organization, 28, 401-426.

Bengtsson, M., \& Kock, S. (2000). Co-opetitive relationships in business networks - to cooperate and compete simultaneously. Industrial Marketing Management, 20(5), 411-426.

Bullinger, A., Neyer, A.-K., Rass, M., \& Moeslein, K. (2010). Community-based innovation contests: where competition meets cooperation. Creativity and Innovation Management, 19(3), 290-303.

Cainelli, G., Evangelista, R., \& Savona, M. (2006). Innovation and economic performance in services: a firmlevel analysis. Cambridge Journal of Economics, 30, 435-458.

Carvalho, L., Costa, T., \& Caiado, J. (2013). Determinants of innovation in a small open economy: a multidimensional perspective. Journal of Business Economics and Management, 14(3), 583-600. 
Carvalho, N., Carvalho, L., \& Nunes, S. (2015). A methodology to measure innovation in European Union through the National Innovation System. International Journal of Innovation and Regional Development, $6(2), 159-180$.

Chen, M. J. (2008). Reconceptualizing the competition-cooperation relationship: a transparadox perspective. Journal of Management Inquiry, 17(4), 288-305.

Chesbrough, H. W., \& Prencipe, A. (2008). Networks of innovation and modularity: a dynamic perspective. International Journal of Technology Management, 42(4), 414-425.

Child, J., \& Faulkner, D. (1998). Strategies of cooperation: managing alliances, networks, and joint ventures. Oxford: Oxford University Press.

Chung, S., \& Kim, G. M. (2003). Performance effects of partnership between manufacturers and suppliers for new product development: the supplier's standpoint. Research Policy, 32(4), 587-603.

Cohen, W., \& Levinthal, D. (1990). Absorptive capacity: a new perspective on learning and innovation. Administrative Science Quarterly, 35, 128-152.

De Luca, L. M., \& Atuahene-Gima, K. (2007). Market knowledge dimensions and crossfunctional collaboration: examining the different routes to product innovation performance. Journal of Marketing, 71, 95-112.

De Marchi, V. (2012). Environmental innovation and R\&D cooperation: empirical evidence from Spanish manufacturing firms. Research Policy, 41(3), 614-623.

Dittrich, K., \& Duysters, G. (2007). Networking as a means to strategy change: the case of open innovation in mobile telephony. Journal of Product Innovation Management, 24(6), 510-521.

Djellal, F., \& Gallouj, F. (1999). Services and the search for relevant innovation indicators: a review of national and international surveys. Science and Public Policy, 26, 218-232.

Drejer, I., \& Jorgensen, B. H. (2005). The dynamic creation of knowledge: analysing public-private collaborations. Technovation, 25(2), 83-94.

Enkel, E., Gassmann, O., \& Chesbrough, H. (2009). Open R\&D and open innovation: exploring the phenomenon. R\&D Management, 39(4), 311-316.

Evangelista, R. (2000). Sectoral patterns of technological change in services. Economics of Innovation and New Technologies, 9, 183-221.

Faria, P., Lima, F., \& Santos, R. (2010). Cooperation in innovation activities: the importance of partners. Research Policy, 39(8), 1082-1092.

Fischer, M. M., \& Varga, A. (2002). Technological innovation and interfirm cooperation: an exploratory analysis using survey data from manufacturing firms in the metropolitan region of Vienna. International Journal of Technology and Management, 24(7/8), 724-742.

Freel, M. S., \& Harrison, R. T. (2006). Innovation and cooperation in the small firm sector: evidence from 'Northern Britain'. Regional Studies, 40(4), 289-305.

Fritsch, M. (2010). Does R\&D-cooperation behavior differ between regions? Industry and Innovation, 10(1), 25-39.

Fritsch, M., \& Lukas, R. (2001). Who cooperates on R\&D? Research Policy, 30(2), 297-312.

Gnyawali, D. R., He, J. Y., \& Madhavan, R. (2006). Impact of co-opetition on firm competitive behavior: an empirical examination. Journal of Management, 32(4), 507-530.

Hair, J., Anderson, R., Tatham, R., \& Black, W. (1998). Multivariate data analysis (5th ed.) Prentice-Hall, International.

Hannelize, J. (2013). Co-innovation through multiple social identity processes: the story of a South African co-op owned business. European Business Review, 25(1), 42-64.

Hollenstein, H. (2003). Innovation modes in the Swiss service sector: a cluster analysis based on firm-level data. Research Policy, 32, 845-863.

Jansen, J. J. P., Tempelaar, M. P., Van Den Bosch, F. A. J., \& Volberda, H. W. (2009). Structural differentiation and ambidexterity: the mediating role of integration mechanisms. Organization Science, 20, 797-811.

Jiménez-Zarco, A. I., Martínez-Ruiz, M. P., \& Izquierdo-Yusta, A. (2011). The impact of market orientation dimensions on client cooperation in the development of new service innovations. European Journal of Marketing, 45(1/2), 43-67.

Katila, R., Rosenberger, J. D., \& Eisenhardt, K. M. (2008). Swimming with sharks: technology ventures, defense mechanisms and corporate relationships. Administrative Science Quarterly, 53(2), 295-332.

Koschatzky, K. (1999). Innovation networks of industry and business-related services relations between innovation intensity of firms and regional inter-firm cooperation. European Planning Studies, 7(6), Special Issue: Innovation Networks, Collective Learning, and Industrial Policy in Regions of Europe, 737-757.

Lado, A., Boyd, N., \& Hanlon, S. (1997). Competition, cooperation and the search for economic rents: a syncretic model. Academy of Management Review, 22(1), 110-141. 
Liker, J. K., Collins, P. D., \& Hull, F. M. (1999). Flexibility and standardization: test of a contingency model of product design-manufacturing integration. Journal of Product Innovation Management, 16(3), 248-267.

Lundvall, B. Å. (1988). Innovation as an interactive process: from user-producer interaction to the national system of innovation. In G. Dosi, C. Freeman, R. Nelson, G. Silverberg, \& L. Soete (Eds.), Technical Change and Economic Theory (pp. 349-369). London: Pinter.

Marsili, O., \& Verspagen, B. (2002). Technology and the dynamics of industrial structure: an empirical mapping of Dutch manufacturing. Industrial and Corporate Change, 11(4), 791-815.

Miotti, L., \& Sachwald, F. (2003). Co-operative R\&D: why and with whom? An integrated framework of analysis. Research Policy, 32, 1481-1499.

Nieto, M. J., \& Santamaria, L. (2007). The importance of diverse collaborative networks for the novelty of product innovation. Technovation, 27(6-7), 367-377.

Paasi, M. (1998). Efficiency of innovation systems in the transition countries. Economic Systems, 22, $217-234$.

Pires, C. P., Sarkar, S., \& Carvalho, L. (2008). Innovation in services - how different from manufacturing? The Service Industries Journal, 28(10), 1339-1356.

Pisano, G. P. (1990). The R\&D boundaries of the firm: an empirical analysis. Administrative Science Quarterly, 35(1), 153-176.

Powell, W. W., Koput, K. W., \& Smith Doerr, L. (1996). Interorganizational collaboration and the locus of innovation: networks of learning in biotechnology. Administrative Science Quarterly, 41(1), 116-145.

Richardson, G. B. (1972). The organisation of industry. Economic Journal, 82, 883-896.

Siedschlag, L., Zhang, X., \& Cahill, B. (2012). The effects of the internationalisation of firms on innovation and productivity. Papers/Economic and Social Research Institute (ESRI), available on http://www.esri. ie/UserFiles/publications/WP363/WP363.pdf

Silva, M. J., \& Leitão, J. (2009). Cooperation in innovation practices among firms in Portugal: do external partners stimulate innovative advances? International Journal of Entrepreneurship and Small Business, 7(4), 391-403.

Srholec, M. (2014). Cooperation and innovative performance of firms: panel data evidence from the Czech Republic, Norway and the UK. Journal of the Knowledge Economy, 5(1), 133-155.

Srholec, M. (2015). Understanding the diversity of cooperation on innovation across countries: multilevel evidence from Europe. Economics of Innovation and New Technology, 24(1-2), 159-182.

Teece, D., Pisano, G., \& Shuen, A. (1997). Dynamic capabilities and strategic management. Strategic Management Journal, 18(7), 509-533.

Tether, B. (2002). Who co-operates for innovation, and why. An empirical analysis. Research Policy, 31, 947-967.

Trigo, A., \& Vence, X. (2012). Scope and patterns of innovation cooperation in Spanish service enterprises. Research Policy, 41(3), 602-613.

Troy, L. C., Hirunyawipada, T., \& Paswan, A. K. (2008). Cross-functional integration and new product success: an empirical investigation of the findings. Journal of Marketing, 72, 132-146.

Von Hippel, E. (1976). The dominant role of users in the scientific instrument innovation process. Research Policy, 5, 212-239.

Vuola, O., \& Hameri, A. P. (2006). Mutually benefiting joint innovation process between industry and bigscience. Technovation, 26(1), 3-12.

Whitley, R. (2002). Developing innovative competences: the role of institutional frameworks. Industrial and Corporate Change, 11(3), 497-528.

World Economic Forum. (2014). Enhancing Europe's competitiveness fostering innovation-driven entrepreneurship in Europe. Insight Report, January 2014.

Zahra, S., \& George, G. (2002). Absorptive capacity: a review, reconceptualization and extension. Academy of Management Review, 27(2), 185-203.

Zeng, S. X., Xie, X. M., \& Tam, C. M. (2010). Relationship between cooperation networks and innovation performance of SMEs. Technovation, 30(3), 181-194. 